\title{
Editorial: Tomorrow the World
}

At Montreal in the late summer of 1983 the United Kingdom had safely reached the finals, but would now have to face either the determination of the German Democratic Republic or the balletic footwork of an artistic team from Argentina. Students of past form knew that any Warsaw Pact government would be ready to put so much money into the game that a Western democratic monarchy could not be expected to compete, and that Argentina would stay the course out of a pride both injured and fostered by a recent defeat in the South Atlantic League.

This was not the Olympic Games or the World Cup, but the quinquennial international contest for the honour of being host country to the World Congress of Philosophy.

The Congress had been held in Oxford in 1930, but that was the only time it had come to the British Isles. In more recent times there had been Venice, Vienna and Varna, Amsterdam, Brussels, Mexico and Düsseldorf. There was strong support for the British cause-in the end strong enough to achieve the victory-but some of the most serious difficulties had to be faced after the choice was made. One of the greatest of these was the general British ignorance of the nature and purpose of the series of World Congresses and of FISP-the Fédération Internationale des Sociétés de Philosophie-which accepts the responsibility of providing continuity and preserving the knowledge of ways and means between one congress and the next. Professor H. D. Lewis and Dr Jonathan Cohen are the two British members of FISP. They have worked hard to overcome ignorance, and the suspicions that ignorance breeds, and they have persuaded a widely representative group of British philosophers and philosophical societies to join together to support and plan the congress. The first public announcement has recently been issued in five official languages. The Eighteenth World Congress of Philosophy will be held in Brighton in August 1988. It is sponsored by the Royal Institute of Philosophy in association with the Aristotelian Society, and with the support of the British Academy and of the principal philosophical societies in England, Scotland, Wales and Ireland. There is a National Policy Committee, of which Professor Lewis is President, and an Organizing Committee under the chairmanship of Professor A. Phillips Griffiths, Director of the Institute.

The second major obstacle has not yet been surmounted. There is a shortage of money at least in the short and mid-term. It is hoped and planned that the fees paid by those attending the congress will eventually cover the costs not met by the donations so far received, but to be 


\section{Editorial}

confident of success, and of being able to publish an appropriate volume or volumes of proceedings, the organizers need substantial further contributions. The Earl of Halsbury, President of the Institute, has worked hard, with some help from a small committee, to raise some of the funds that are needed. Helpful contributions have been received from the Institute and the Aristotelian Society, and from a number of public companies, trusts, institutions and private individuals. The Government has made a contribution, not on an Eastern European scale, but a ministerial mite that has helped to prime the pump.

Some British philosophers will remain sceptical of the value of any such gathering. Their doubts can be answered only by making thoughtful and effective provision for a congress that will have strong representation of the home countries but will also serve the international objectives that FISP was founded to pursue. The 'first circular' is closely based in form and style on those issued by earlier planning committees. A distinctive content can be provided only if philosophers and philosophical societies will now respond to its invitation to provide papers and speakers for the 'Round Tables' and 'Poster Sessions' and other meetings which will supplement the plenary sessions and colloquia and symposia which the Programme Committee is actively planning. Copies of the circular and other information may be obtained from Conference Services Ltd, 3-5 Bute Street, London SW7 3EY (telephone 5844226).

We look forward to seeing many of our members and readers at Brighton in 1988. If the congress is to be successful it needs a large attendance of philosophers from the host countries to add to the substantial numbers of overseas visitors who are confidently expected.

In all five languages the main theme has been stated with deliberate ambiguity: 'The Philosophical Understanding of Human Beings'. 